\title{
Platform strategies: how the position in the network drives success
}

\author{
Elena Pellizzoni \\ School of Management, Politecnico di Milano, Milano, Italy \\ Piazza L. da Vinci, 3220133 Milano Italy - Tel: +39 0223993967 - \\ elena.pellizzoni@polimi.it - http://orcid.org/0000-0002-5016-4084
}

Daniel Trabucchi (corresponding author)

School of Management, Politecnico di Milano, Milano, Italy

Piazza L. da Vinci, 3220133 Milano Italy - Tel: +39 0223993947 -

daniel.trabucchi@polimi.it - http://orcid.org/0000-0003-1290-8043

\section{Tommaso Buganza}

School of Management, Politecnico di Milano, Milano, Italy

Piazza L. da Vinci, 3220133 Milano Italy - Tel: +39 0223993947 -

tommaso.buganza@polimi.it - http://orcid.org/0000-0002-8170-9016

Scholars have focused on platform strategies for a long time, moving from a product perspective to an industry-wide one. In particular, the decision to open the platform to external complementors has been studied through the perspective of platform leadership. The digital age is now moving from a closed approach versus an open approach. Is being a platform leader still imperative or is participating in a network of existing platforms still a suitable strategy as well? What kind of collaborations within an ecosystem leads to better performances? Leveraging social network analysis is performed within the network formed by mobile apps in the Health and Fitness category; this research shows how the decision of being (or not) a platform provider has an impact on the performances, but the position within the network mediates this impact. Based on the results obtained, research and managerial implications can be established.

Keywords: Platform Strategies; Ecosystem; Social Network Analysis; Coopetition. 


\section{Introduction}

Over the last decade, the role of platforms in our economy has consistently changed. Initially, 'platform' was used in the product development field to describe projects that created a common base for a new family of products for a single firm (Meyer and Lehnerd, 1997). Opening the platform to external players was key and the logical next step (Chesbrough, 2003). Gawer and Cusumano define these external platforms as 'products, services, or technologies developed by one or more firms, and which serve as foundations upon which a larger number of firms can build further complementary innovations and potentially generate network effects' (Gawer and Cusumano, 2014, p. 420).

The decision to open the platform, to give a chance to external players to foster innovation through it, has been a key strategic step in the path to success for several companies. Microsoft is one of the most brilliant examples, externalizing the idea generation, design and implementation of the majority of applications that made Windows the first operating system in the world (Gawer and Cusumano, 2002). Being the platform leader was considered to be the holy grail for success, and researchers focused on how to pursue this strategy (Gawer and Cusumano, 2002). We often witnessed winner-takes-all dynamics (Schilling, 2002), where a few platforms shared huge markets (e.g., Motorola and Intel for processors; Windows, Unix, and MacOS for operating systems). Nowadays, we still have similar dynamics (iOS and Android), but digital technologies are rapidly changing the scenario. The boundaries between platform providers (PPs) and complementors are fading away, along with the clear distinction between competition and cooperation. Companies can easily share information and knowledge with an increasing number of players, advancing the boundaries of what can 
be done outside the firm's borders (Whelan et al., 2010). Several platforms compete and cooperate to create products that lead to complementary innovations and network effects, going beyond the technology platform itself. Think about different social networks: they propose alternative ecosystems and struggle to attract users, but they allow and even encourage cross-publishing of contents.

This radical contextual shift forces us to question if the platform leadership strategy is still valuable today (Evans and Schmalansee, 2016). Going beyond the company boundaries is not an option anymore, it is a must (Chesbrough, 2003). Is being a platform leader still an imperative or is participating in a network of existing platforms still a suitable strategy as well? What kind of collaborations within an ecosystem leads to better performances?

This research aims to better understand the impact of strategic alternatives in a platform-based environment, digging in the decision to become a PP or to join an existing platform, a decision that several players in the digital world need to face.

The paper is built around a social network analysis (SNA) of the kinds of relationships existing between different app providers in the health and fitness industry. Different roles are considered, since each app developer may be or not a PP. The results contribute to the literature on platform strategies, statistically showing the impact of the platform strategy to the performances (Gawer and Cusumano, 2002; Iansiti and Levien, 2004). It shows that the position in the network (Position in the Network) that results from the links between different providers and multiple complementors have an impact on performances, showing the relevance of this position among the different antecedents of market performances in a platform-based environment (Perrons, 2009; den Hartigh et al., 2016). 


\section{Theoretical Background}

Industry platforms involve three main types of players: consumers, developers and the PP (Van Alstyne et al., 2016). Focusing on the business side, there are three main categories (Gawer and Cusumano, 2002): platform leaders (companies that drive industry-wide innovation for an evolving system of separately developed pieces of technology), wannabes (PPs that want to be platform leaders but they do not drive the industries) and complementors (companies that make ancillary products that expand the platform's market), which can be reduced to just two categories from a strategic perspective: PPs and complementors. Gawer and Cusumano (2002) define the platform leader as a PP who attracts the highest number of complementors and users to its platform, leveraging network effects. Iansiti and Levien (2004) used different words to define the PP, describing them as 'keystone firms' who provide a stable and predictable set of shared assets that other organizations use to build their offerings, enlarging the perspectives of these firms in broader ecosystems.

Due to the relevance of network effects in this kind of markets, a winner-takes-all dynamic is likely to occur (Schilling, 2002; Srinivasan et al., 2004). This expected output leads to harsh competition among different PPs (Boudreau, 2012), creating several wannabes aiming to become the platform leader and to control the market (leading to better performances).

Gawer and Cusumano (2002) also identified four levers that wannabes could leverage to become platform leaders: the scope, product technology, relationships with external complementors and wannabes and internal organizations. The third lever is relevant to our study: the PP can decide which kind of strategy to implement in relationships with other players (Boudreau, 2012).

The co-existence of multiple platforms in the same industry is becoming more common, challenging the traditional winner-takes-all structure of platform markets 
(Eisenmann et al., 2011). Cusumano (2010) explains that as long as there is space for companies to differentiate their platform offerings, and consumers can use more than one platform, then it is unlikely for one dominant platform to emerge. Multiple platforms can coexist because of: asymmetric or local network effects (Shankar and Bayus, 2003); low costs of adopting multiple platforms (Evans and Schmalansee, 2016); or differentiated consumer preferences (Armstrong and Wright, 2007).

Chesbrough (2003) proposed to remove companies' barriers to foster innovation leveraging external stimuli. Similarly, recent literature builds on the concept of Market for Ideas aiming to bridge - relying on a platform structure - people having innovative ideas and companies searching for them (Dushnitsky and Klueter, 2011; Garavelli et al., 2013; Natalicchio et al., 2014). This is showing how the concept of platform moved gradually from a close to an open perspective. This is aligned with the mindset of an industry platform. According to Gawer (2014), 'as platform interfaces become more open, more agents will be attracted into the platform ecosystem, and the platform leader will be able to access a larger set of potentially complementary innovative capabilities'. A platform's market, though, is not isolated from others, and sometimes PPs of 'neighboring' markets extend the scope of the offering to include the functionality central to the offering of a neighboring platform (Cennamo, 2014). Eisenmann and colleagues (2011) defined the concept of platform envelopment as the action performed by a PP that decides to enter into another PP's market by bundling its functionality with one of the targets, to leverage on shared users and common components. Envelopment happens when a platform incumbent in a market identifies complementarities between its platform and the platform in a neighboring market, the former PP integrates the latter platform's functionality into its platform, providing value that is a combination of the two. 
When PPs and complementors must navigate a complex strategic landscape where both competition and collaboration occur among the same players (Gawer and Cusumano, 2014), a coopetition strategy takes place (Hunt, 1997, Bengtsson and Kock, 2000). This strategy implies that cooperation and competition merge to form a new kind of strategic interdependence between firms, giving rise to a 'coopetitive system of value creation'.

This evolution of platform markets leads to a clear question: which kind of platform strategy should a firm implement? Is it better to be a PP (opening the boundaries and allowing all complementors to connect) or joining existing platforms being a complementor (connecting to different platforms)? In terms of performances, which is better? The literature on platforms suggests that being a PP can lead to platform leadership and thus better performances (Gawer and Cusumano, 2002). Nevertheless, this may not be the only valuable strategy in a world of coopeting and interoperating digital platforms where a fantastic amount of data and value can be created and exchanged.

\section{Hypotheses Development}

In this study, we investigate the Platform strategy as the antecedents or drivers of the performances of the company. Companies aiming to compete in the platform-based environment face a significant strategic decision: being a PP or being a complementor, contributing in the development of one (or more) platform(s) created and managed by another player in the system (Gawer and Cusumano, 2002).

There are many companies that, deciding to provide a platform open to other complementors to offer a particular kind of service, proved to be more successful than companies that worked on their own or joined platforms provided by someone else. Recent examples may be Airbnb with its multi-million homes for rent in comparison with the thousands of properties of the much older Starwood, or their market evaluations 
(almost 30 billion dollars the first, roughly 12 the ladder), similar cases may be presented for Uber VS Hertz or Alibaba VS Walmart (Libert et al., 2016).

Scholars seem to suggest that being a PP is positively linked with performances. Theories regarding the role of the provider in platform leadership (Gawer and Cusumano, 2002) underpins this direct positive relationship. The advantages for firms the firms that lead the platform creation process have been widely studied in the literature, talking for example of keystone advantage (Iansiti and Levien, 2004) or showing the benefit of network orchestration (Libert et al., 2016). Setting the platform may lead to the chance to manage innovation hubs (Nambisan and Sawhney, 2011).

Furthermore, research discusses also different success factors that PPs may rely on to be even more successful, such as being particularly efficient in linking with the complements or for their innovative abilities (Lee et al., 2010). Also, the kind of relationship that the PP can create with its complementors is relevant to emerge as a crucial PP (Perrons, 2009). Different ways to manage the governance of the platform, for example, both through centralized or distributed networks, may lead to positive outcomes (den Hartigh et al., 2016).

All these studies and the related streams seem to suggest a relationship between the chance to provide a platform and the firm's success, since being a PP leads to peculiar benefits - in comparison with the firms that join the platform as a complementor. Fist, the chance to aim for a winner-takes-all configuration (Schilling, 2002). Second, the chance to rely on the network effects generated and therefore see a consistent growth regarding the platform value (Katz and Shapiro, 1985). Nevertheless, PPs have also the chance to control the relations existing between the parties and to leverage innovations proposed by the complementors, capturing at least part of their value (Gawer and Cusumano, 2014). Therefore, this study aims at probing the statistical relevance of this 
relation, something that has prompted significant academic debates over the last decade. Leveraging these theories, our first hypothesis (H1) is stated as follows:

H1: The choice of being a PP has a direct positive impact on performances.

Lately, Gawer (2014) has focused on the possible competition between a PP and its complementors, which is a typical situation in platform-based ecosystems. Also in this case different examples may be easily found in the empirical world. Google and Apple are two PPs with their operating systems (Android and iOS) that are open to external complementors. Nevertheless, Google works also as a complementor for the iOS platform through services such as the search engine or Google Maps. This means that at the same time they compete through the operating systems as platforms and may act as complementor one for the other. Players' changing roles within platform ecosystems, and associated changing patterns of competition and collaboration, are common features of ecosystems (Iansiti and Levien, 2004); these features are particularly important for digital platforms, as the transition to increasingly digitalized and modularized design, together with the availability of low-cost Internet-based communication, is creating a 'paradigm shift' with innovation not being restricted to producers anymore, but being influenced or even driven by users, organized in distributed and collaborative innovation communities (Baldwin and von Hippel, 2011).

The increasing relevance of platform-based economies and the dynamic relationship among different actors in the field are rising the chance that the same company can act both as PP and complementor on different platforms. This is leading to the creation of a complex network of companies, where different platforms, created by different PPs, are linked together through complementors (belonging to different platforms) and being 
providers and complementors at the same time. In such an environment, a higher number of connections will result in a higher opportunity to exchange (inbound and/or outbound) data and value. The relevance of being a PP could change. It might be mediated by another factor (positioning in the network), especially in the case of the co-existence of several platforms. Being a provider means developing an infrastructure, taking the risk of the entire project and having the responsibility to guide the platform to the critical mass. Complementors, however, have the chance to select not only one platform but also to apply a multi-homing strategy (Suarez, 2005) being on several platforms at the same time with a relatively low investment. Finally, platforms can also act as complementors and connect to other platforms: in this way, they gain both platform and complementor benefits. At the same time, a complementor can be hyper-connected, even without implementing a platform strategy. The hyper-connection may be beneficial as well. In such an environment, the quality and the number of linkages (the positioning within the network) may have a significant impact on performance. This research supports that the Platform strategy has an impact on the Position in the network, and that a more central position might improve the Performance. Adding both direct relations, this paper can derive an indirect link between the Platform Strategy and the Performance with the Position in the Network with a mediator role (e.g., Felipe et al., 2016). Based on this logic an previous research, this study hypothesized that (Figure 1):

$\mathrm{H} 2$ : The position in the network mediates the relationship between the platform strategy and performance.

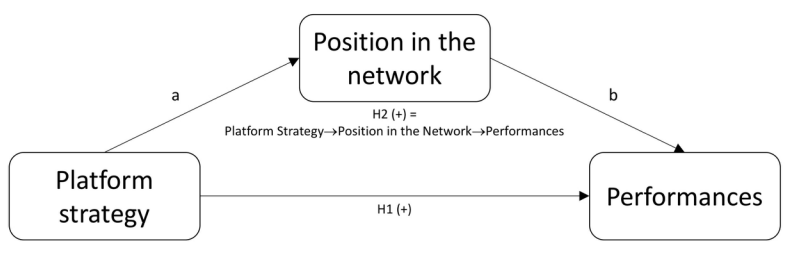

Figure 1-The model 


\section{Data and Methods}

\section{Sample and data collection}

The empirical field of this study is the mobile applications industry, where implementing platforms strategies is always more common, and it is getting growing attention from management scholars (Trabucchi et al., 2017). Mobile apps are particularly interesting because can gather a considerable amount and variety of data during the service delivery (Trabucchi et al., 2018). These data are often used to implement platform strategies by providing their API (Application Programming Interface) to external developers to enable them to create their apps on it. Among the different categories of apps, we focus on the Health and Fitness. This category of mobile apps has been previously studied dealing with platform-based business models and the usage of data (Varshney, 2014; Buganza et al., 2015; Trabucchi et al., 2017). Indeed, companies often use the data gathered by other players to enhance their offering and to provide a broader experience integrating different kinds of information into the system, acting in a provider-complementor relationship.

The process of data collection was completed over a period of six months, from April to September 2015. The data gathering was manually done on secondary sources following a two-step process. Firstly, information on connections between apps was retrieved to build the network used to gather data on the position of apps. The network of apps was built starting from RunKeeper (the first Health and Fitness app to provide open an API, therefore becoming a PP) and adding the apps that were connected to RunKeeper, and the ones that were connected to them, and so on until there were no further connections available. In the second step, data on the performance of each app were retrieved from the app store, AppAnnie and the app websites.

The initial sample is composed of apps from the iTunes Store, Google Play Store, and Windows App Store. It contains apps that are both PPs (31 in total - meaning that 
they provide their APIs) and apps that are complementors to the PPs (250 in total). These applications represent the complete network. The analysis was then constrained to 169 apps, selecting only apps available on the Google Play Store since it allows us to know the number of downloads (measure of performance). The final dataset is composed of 29 platforms and 140 complementors.

\section{Method}

The data analysis was done in a two-step process. Firstly, SNA was performed to study the network and retrieve information on the position in the network through Pajek software (Freeman, 1978; Wellman and Berkowitz, 1988; Doreian, 2001). The SNA is gaining attention in the management literature (Arenas-Màarquez et al., 2014; Hu et al., 2015) has been used in literature in relation to innovation performances, where it allowed us to understand how different positions in a network affected the different levels of innovation of actors involved in the network (Salman and Saives, 2005). In this research, the SNA is used in relation to successful performances instead of innovation performances to explore what affects the different levels of success of actors involved in a network of multiple platforms (Figure 2).

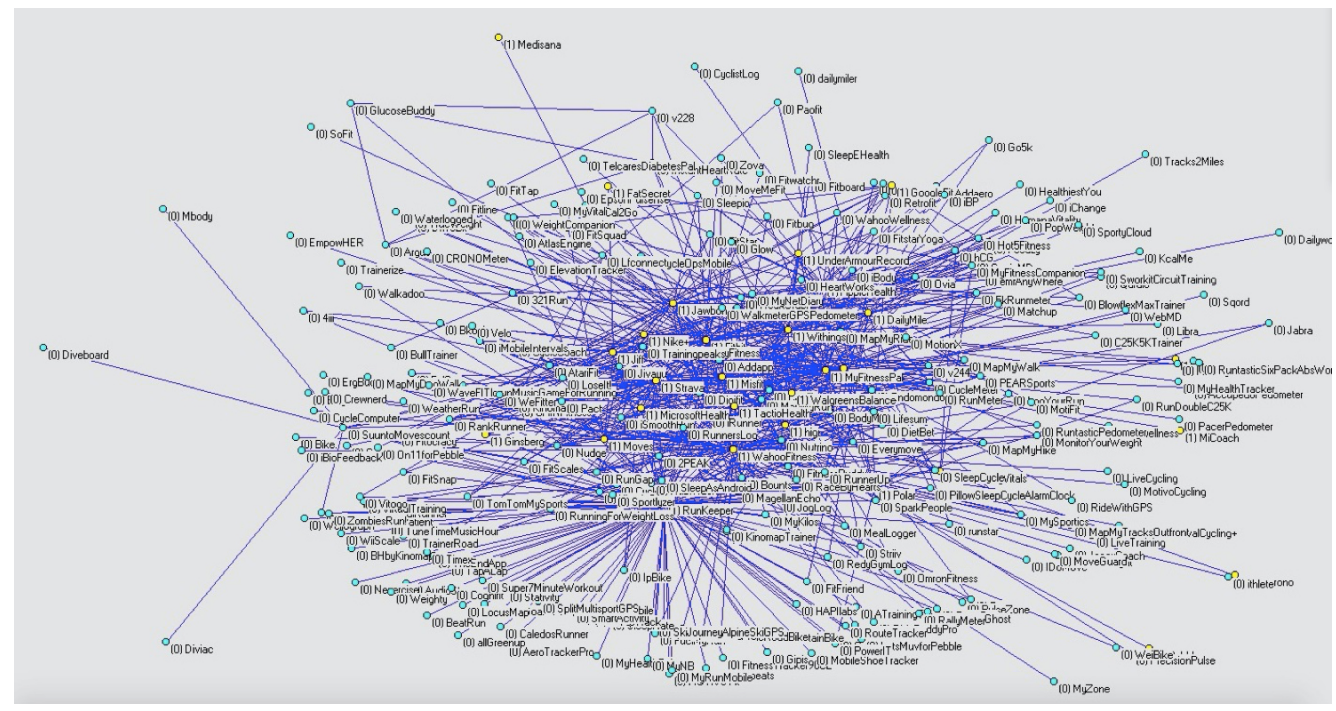

Figure 2-Visualization in Pajek of the network 
Secondly, to test the theoretical model, we used structural equation modeling, applying the partial least square (PLS) approach through SmartPLS v3.0 (Ringle et al., 2005; Chin, 1998). PLS-SEM is suggested when the research objective is prediction and theory development, as in our research (Hair et al., 2011). Moreover, it can manage small samples and not normally distributed variables (Reinartz et al., 2009). Considering then that PLS involves no assumptions about the population or scale of measurement, it also works with nominal scaled variables, such as our construct of Platform strategy (Fornell and Bookstein, 1982; Peng and Lai, 2012) and it allows for the unrestricted use of single item constructs (Ringle et al., 2012; Petrescu, 2013). Finally, the sample of 169 apps is larger than the minimum sample size requested by PLS algorithm and is ten times the number of indicators used to measure a single construct or structural paths direct to a latent construct in the structural model (Wasko and Faraj, 2005). Subsequently, nonparametric bootstrapping with 200 replications (no significant change to obtain the standard errors) was applied to define statistical significance of path coefficients (Hair et al., 2011).

\section{Operationalization of construct}

Constructs were operationalized by validated measurements, when available, or by leveraging literature definitions.

Platform Strategy. Two different strategies can be adopted in a platform-based environment: being a PP or being a complementor (Gawer and Cusumano, 2002; Basole and Karla, 2011). In the selected empirical field, a PP is an app that has opened its API to others to enable them to work on its platform and data. The other apps are considered complementors. 
Position in the Network. An individual's network place or position in the overall pattern of relations determines what information that person has access to or, correspondingly, whom he or she is in a position to influence (Watts, 2003). Similarly, app Position in the Network determines what data that app could use to create value. Therefore, the notion of centrality captures the 'importance' of the network actors (Faust, 1997; Freeman, 1978). Two measures of centrality are suggested in the literature: degree centrality (DC), which measures the number of connections a node has to other nodes, and betweenness centrality (BC), which measures the shortest number of paths passing through a given actor in a network (Freeman, 1978; Borgatti, 2005).

Performance. As suggested by Crowston et al. (2003), a simple measure of user success is the number of downloads. Operationalization is done in literature (Petsas et al., 2013; Lee and Raghu, 2014), arguing that instead of measuring the number of actual users, it is sufficient to count the potential number of users of the software, which they label popularity (DeLone and McLean, 1992; Subramaniam et al., 2005). In particular, regarding the mobile apps field download is often considered as performance measure, since other metrics (active users, number of users) depend on the specificity of the kind of service (Chen et al., 2017). Google's Play Store gives an approximation, indicating the range of downloads that the application has reached. As suggested in the literature, the middle value of the range can be used as a proxy to assess the penetration of the product, since it outlines an average number of people who have obtained the application (Corral and Fronza, 2015).

Controls. Tests with perceived quality (app rating on Google's Play Store), word of mouth (number of likes on Facebook) and price (app price in euros) as control variables were performed. Both perceived quality and price are correlated to the perceived value of the product, determining the purchaser's willingness to buy the product (Monroe, 1979). 
Moreover, also word of mouth can have a potential impact on the performances of innovative products and services (Richins and Root-Shaffer, 1988; Kim and Hanssens, 2017).

\section{Results}

\section{Measurement model}

To test the validity of construct measures, several analyses were performed, and the measurement model meets all common requirements. Internal consistency reliability, indicator reliability, and convergent validity were tested.

First, the reliability is confirmed by the indicator standards loading higher than 0.7. (Table 1). Secondly, each value of Composite reliability and Cronbach's alfa were higher than commonly agreed thresholds, showing high construct reliability (Table 2). Moreover, the Average Variance Extracted $(\mathrm{AVE}=.960)$ is higher than 0.5 , indicating a high convergent validity (Fornell and Larcker, 1981; Vinzi et al., 2010; Cepeda-Carrion et al. 2016).

Discriminant validity was assessed by observing if each construct shared more variance with its items than other constructs in the model (Chin, 1998), but also with Fornell and Larcker methods (Fornell and Larcker, 1981). As shown in Tables 1 and 3, measure loads are higher on the construct of interest than on any other factors, and AVE is higher than the constructs highest shared variance, thus supporting the validity of the model. Finally, the discriminant validity is also tested with the Heterotrait-Monotrait Ratio (HTMT). The values of Table 4 show measurements below 0.85 which is the more conservative critical HTMT value (Henseler et al., 2015).

\begin{tabular}{ccccccc}
\hline & Performance & $\begin{array}{c}\text { Word of } \\
\text { Mouth }\end{array}$ & $\begin{array}{c}\text { Position in the } \\
\text { network }\end{array}$ & Price & $\begin{array}{c}\text { Platform } \\
\text { Strategy }\end{array}$ & $\begin{array}{c}\text { Perceived } \\
\text { Quality }\end{array}$ \\
\hline PS & .339 & .247 & .479 & -.081 & $\mathbf{1 . 0 0 0}$ & -.073 \\
$\mathrm{Pe}$ & $\mathbf{1 . 0 0 0}$ & .216 & .407 & -.065 & .339 & .126 \\
\hline
\end{tabular}




\begin{tabular}{lcccccc}
\hline PQ & .126 & -.097 & -.034 & -.039 & -.073 & $\mathbf{1 . 0 0 0}$ \\
Pr & -.065 & -.011 & -.053 & $\mathbf{1 . 0 0 0}$ & -.081 & -.039 \\
WoM & .216 & $\mathbf{1 . 0 0 0}$ & .188 & -.011 & .247 & -.097 \\
DC & .431 & .218 & $\mathbf{. 9 8 5}$ & -.065 & .539 & -.034 \\
BC & .357 & .140 & $\mathbf{. 9 7 4}$ & -.036 & .379 & -.034 \\
\hline
\end{tabular}

Table 1-Loading and cross Loading. The bolded values are items related with constructs of the column.

\begin{tabular}{lccc}
\hline & $\begin{array}{c}\text { Composite } \\
\text { Reliability }\end{array}$ & Cronbach's Alpha & AVE \\
\hline Performance & 1,000 & 1,000 & 1,000 \\
Word of Mouth & 1,000 & 1,000 & 1,000 \\
Position in the network & 0,980 & 0,959 & 0,960 \\
Price & 1,000 & 1,000 & 1,000 \\
Platform Strategy & 1,000 & 1,000 & 1,000 \\
Perceived Quality & 1,000 & 1,000 & 1,000 \\
\hline
\end{tabular}

Table 2-Composite Reliability, Cronbach alphas, and AVE.

\begin{tabular}{|c|c|c|c|c|c|c|}
\hline & Performance & $\begin{array}{l}\text { Word of } \\
\text { Mouth }\end{array}$ & $\begin{array}{l}\text { Position in the } \\
\text { network }\end{array}$ & Price & $\begin{array}{l}\text { Platform } \\
\text { Strategy }\end{array}$ & $\begin{array}{c}\text { Perceived } \\
\text { Quality }\end{array}$ \\
\hline Performance & 1.000 & & & & & \\
\hline $\begin{array}{l}\text { Word of } \\
\text { Mouth }\end{array}$ & .216 & 1.000 & & & & \\
\hline $\begin{array}{l}\text { Position in the } \\
\text { network }\end{array}$ & .407 & .188 & .922 & & & \\
\hline Price & -.065 & -.011 & -.053 & 1.000 & & \\
\hline $\begin{array}{l}\text { Platform } \\
\text { Strategy }\end{array}$ & .339 & .247 & .479 & -.081 & 1.000 & \\
\hline $\begin{array}{l}\text { Perceived } \\
\text { Quality }\end{array}$ & .126 & -.097 & -.034 & -.039 & -.073 & 1.000 \\
\hline
\end{tabular}

Table 3-Latent Variable Correlation. The bolded diagonal values are the square roots of the AVEs.

\begin{tabular}{lcccccc}
\hline & Performance & $\begin{array}{c}\text { Word of } \\
\text { Mouth }\end{array}$ & $\begin{array}{c}\text { Position in the } \\
\text { network }\end{array}$ & Price & $\begin{array}{c}\text { Platform } \\
\text { Strategy }\end{array}$ & $\begin{array}{c}\text { Perceived } \\
\text { Quality }\end{array}$ \\
\hline $\begin{array}{l}\text { Number of } \\
\text { downloads }\end{array}$ & & & & & \\
$\begin{array}{l}\text { Word of } \\
\text { Mouth }\end{array}$ & .216 & & & & \\
$\begin{array}{l}\text { Position in } \\
\text { the } \\
\text { network }\end{array}$ & .411 & .186 & & & \\
Price & .065 & .011 & .052 & & \\
\hline
\end{tabular}




\begin{tabular}{llllll}
\hline Platform & .339 & .247 & .478 & .081 & \\
$\begin{array}{l}\text { Strategy } \\
\text { Perceived }\end{array}$ & .126 & .097 & .035 & .039 & .073 \\
Quality & .126 & .035 \\
\hline
\end{tabular}

Table 4-Heterotrait-Monotrait Ratio (HTMT)

\section{Structural model}

Three PLS path models are presented (Table 5). First, the model with only the control variables is tested (Model 0), then to verify the first hypothesis, the direct impact of Strategy on Performance is analyzed (Model 1) and the mediation effect (HP2) is examined afterward (Model 2). The t-values of the path coefficients are generated using the 200-iteration bootstrapping technique. We verified the validity of the results by performing bootstrapping using different resampling schemes (250, 500-iteration) (Ahuja et al., 2003).

\begin{tabular}{|c|c|c|c|}
\hline & MODEL 0 & MODEL 1 & MODEL 2 \\
\hline \multicolumn{4}{|l|}{ Path } \\
\hline Perceived Quality $\rightarrow$ Performance & $.146^{\text {n.s. }}$ & $.160^{*}$ & $.160^{*}$ \\
\hline Word of Mouth $\rightarrow$ Performance & $.229^{\text {n.s. }}$ & $.155^{\text {n.s. }}$ & $.132^{\text {n.s. }}$ \\
\hline Price $\rightarrow$ Performance & $-.057^{*}$ & $-.032^{\text {n.s. }}$ & $-.027^{\text {n.s. }}$ \\
\hline Platform Strategy $\rightarrow$ Performance & & $.310^{* *}$ & $.169^{\text {n.s. }}$ \\
\hline Position in the network $\rightarrow$ Performance & & & $.305^{*}$ \\
\hline Platform Strategy $\rightarrow$ Position in the network & & & $.479^{* * *}$ \\
\hline \multicolumn{4}{|c|}{ n.s.:not significant; ${ }^{*}: \mathrm{P}<0.050 ; * *: \mathrm{P}<0.010 ;{ }^{* * *}: \mathrm{P}<0.001}$. \\
\hline \multicolumn{4}{|l|}{$\overline{R^{2}}$} \\
\hline Performance & .071 & .161 & .232 \\
\hline Position in the network & & & .230 \\
\hline
\end{tabular}


In line with hypothesis H1, we found that the Platform Strategy positively affects the Performance (Model 1: $\beta=.310 ; \mathrm{t}=2.28$ ). Nevertheless, when the Position in the Network is added to the model, the direct effect becomes not significant (Model 2). On the contrary, Platform Strategy significantly enhances the Position in the Network (Model 2: $\beta=.479 ; t=8.85$ ) which positively affects the Performance (Model $2: \beta=.305 ; t=1.96)$, showing a mediation effect. Therefore, Model 2 shows how the path a and $\mathrm{b}$ (Figure 1) are significant, suggesting an indirect effect of Platform Strategy on Performances via the Position in the Network as a mediator (Felipe et al., 2016). Hypothesis 2 is accepted. Moreover, the analysis shows a full mediation effect of the Position in the Network, since the direct effect between Platform Strategy and Performance is not significant in Model 2 (Baron and Kenny, 1986). As suggested by Baron and Kenny (1986), a Sobel Test was performed, and mediation is confirmed (Sobel Test Statistic: 2.011; sign.:0.04) (Sobel, 1982). The bias-corrected confidence intervals for the mediation effect does not include 0 value (bias-corrected $\mathrm{CI}[5 \%]=.018$ and bias-corrected $\mathrm{CI}[95 \%]=.291$ ); consequently the mediation effect is significative (Carrión et al., 2017).

The overall quality of the model is measured by looking at the R-squared value in the final dependent construct (Peng and Lai, 2012). As Table 5 shows, moving from Model 0 to Model 2 R-squared increases, presenting a better explanatory value of the dependent variables.

\section{Discussion}

We challenge the traditional relationship that associates the decision of being a PP to greater performances on the market and, consequently, to the platform leadership position (Gawer and Cusumano, 2002). We often do not find any more single or few platforms that dominate the ecosystem. We often find different platforms coexisting and actors playing the double role of PPs and complementors (Shankar and Bayus, 2003; Suarez, 
2005). These dynamics, along with the increasing attention that is being paid to open strategies in platform-based industries (Eisenmann et al., 2011), prompt us to conclude that being connected might be even more important than being a PP.

Our results confirm the traditional relationship (Gawer and Cusumano, 2002) that links the decision to be a PP and performance (H1), measured by the number of downloads in the mobile application industry. Nevertheless, they prove the full mediating role of the Position in the Network (H2). Depending on the positioning in the network, both PPs and complementors can achieve optimal performance. Consider, for example, RunKeeper and Endomondo - two of the most successful apps in the Health and Fitness category - they apply two completely different strategies. RunKeeper is a PP: through their public API, they created Health Graph, a platform to collect and share the data coming from hundreds of other complementors. On the other hand, Endomondo leverages an open strategy (being linked with several platforms and complementors), without providing its API. In both cases, as shown in Figure 3, they are in a dense area of the network and they have comparable performances (both of them have more than 10 million downloads on Google's Play Store).

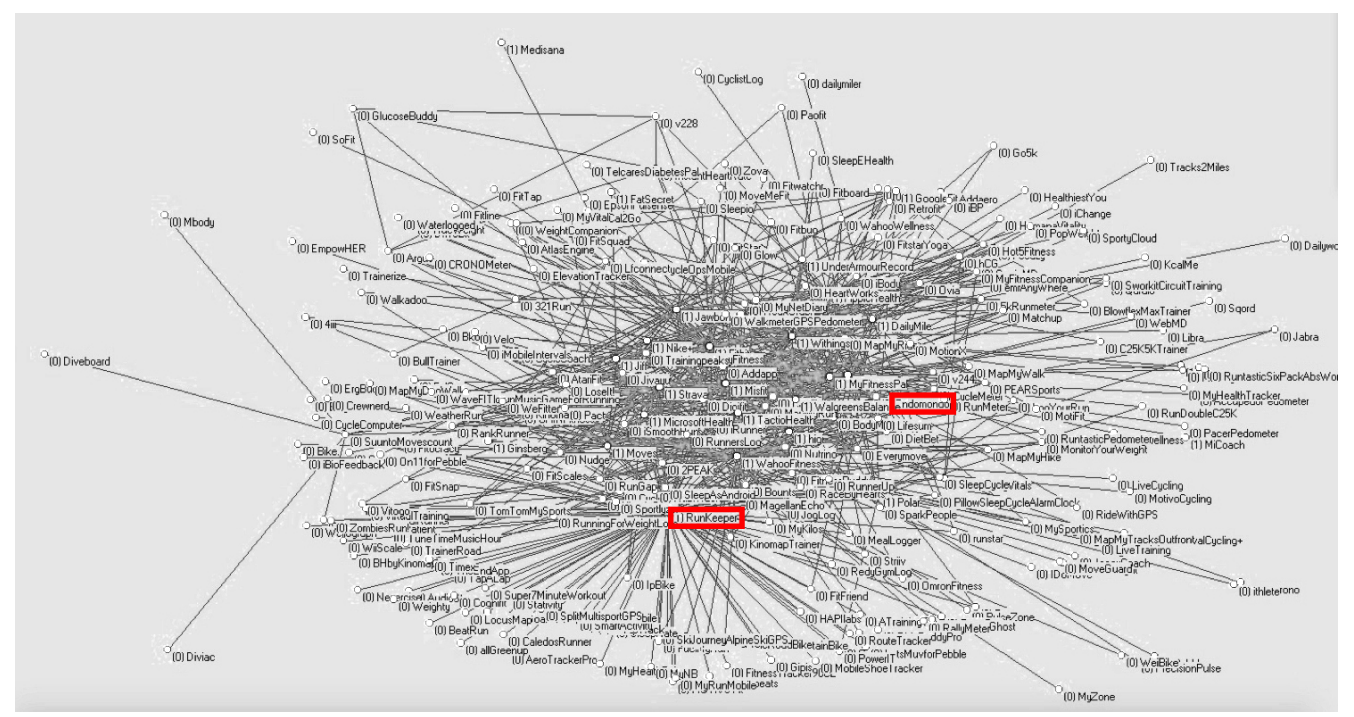

Figure 3-RunKeeper and Endomondo in the network 
Instead of searching for platform leadership, popular companies in our sample rely on different strategies based on positioning. They leverage coopetition to achieve a broader network of relationships and increase the visibility and the volume of usable data (Hunt, 1996, Bengtsson and Kock, 2000). These data, though, are all similar, even if they are retrieved from many more users (they are all running stats). It is interesting to observe that popular companies in the sample also look for a higher variety of data by connecting with PPs/complementors in adjacent activity fields by applying a typical platform envelopment strategy (Eisenmann et al., 2011) (RunKeeper is linked with MyFitnessPal, which is another PP focused on gathering information about diet).

The implementation of similar strategies over platform leadership is not surprising at all in a digital innovation environment. Volume and variety are two of the five characteristics of big data (BD) (McAfee and Brynjolfsson 2012) which are a major source of value in such an environment. Even platforms need to connect to other platforms to increase their potential value; connections (positioning) are turning out to be more relevant than being a keystone in a small ecosystem.

\section{Conclusions}

This research offers a contribution to the literature on platform strategies, showing how the decision to be a PP (Gawer and Cusumano, 2002) may not be enough anymore. The open innovation paradigm (Cherbourg, 2003) - in highly competitive, digital and platform-based environments - leads to the creation of complex networks of relationship leveraging coopetition strategies (Hunt, 1996, Bengtsson and Kock, 2000) where the positioning opens new challenges. Accessing BD is an opportunity and not a success factor per se. Practitioners and academics are currently investigating how to create and capture value from BD (Trabucchi et al., 2017, 2018; Carbonell et al., 2017) and our data 
corroborates this issue. Being in the right position within the network is associated with more popularity, but there is no statistical relationship between the number of downloads and the quality perceived by users (control variable).

In other words, this research offers a contribution to the literature on platform management in different ways. First, it offers a quantitative perspective on the link between the decision to act as a PP - instead of as a complementor - and the performances, which is widely suggested by the literature on platform leadership (Gawer and Cusumano, 2002; Iansiti and Levien, 2004). Second, a number of antecedents to the performances of firms in platform-based environment have been previously found, such as network effect or the innovative abilities of the provider (Perrons, 2009; den Hartigh et al., 2016), our research extends this list showing the role of the Position in the Network which is guided by the decision to be a PP. Finally, since our model presents a full mediation, this research contributes to theory showing that it is possible to reach the performances of a PP working only on the position and not necessarily providing the platform, providing a counterintuitive result if compared to previous literature on platform leadership (Gawer and Cusumano, 2002).

From a managerial perspective, this research contributes to practitioners dealing with platform strategies, and in particular with the decision to become PP or join an existing platform as complementor. Our result suggests them to consider also the kind of links they have in the network, and not only the decision itself. It is important to highlight that even if the Position in the Network can help companies to reach a high number of users, it does not imply that they are going to like and use their apps. To build a sustainable strategy, it is not enough to aim to be in a specific position within the network, which could be considered a necessary (but not sufficient) condition for success. 
Regarding limitations, our dataset relies on observations collected at one point in time, a longitudinal approach may be suitable for further research. It focuses only on the Health and Fitness, reducing the generalizability of the results. Future research may replicate the study in other fields. This research focuses on the position that each app has in the overall network, may be interesting to understand the antecedents of the position, considering different strategies implemented by the firm or characteristics of the organization that has an impact on the Position in the Network. Finally, performances are operationalized through the number of downloads, and it would be interesting to consider other measures of success.

\section{References}

Arenas-Márquez, Francisco José, M. Rocío Martínez-Torres, and SL Toral. 2014. "Electronic Word-of-Mouth Communities from the Perspective of Social Network Analysis." Technology Analysis \& Strategic Management 26(8):927-942.

Armstrong, M. and J. Wright. 2007. "Two-Sided Markets, Competitive Bottlenecks and Exclusive Contracts." Economic Theory 32(2):353-380.

Baldwin, C. and E. von Hippel. 2011. "Modeling a Paradigm Shift: From Producer Innovation to User and Open Collaborative Innovation." Organization Science 22(6):1399-1417.

Baron, R. M. and D. A. Kenny. 1986. "The Moderator-Mediator Variable Distinction in Social Psychological Research. Conceptual, Strategic, and Statistical Considerations." Journal of Personality and Social Psychology 51(6):1173-1182.

Basole, Rahul C. and Jürgen Karla. 2011. "On the Evolution of Mobile Platform Ecosystem Structure and Strategy." Business \& Information Systems Engineering 3(5):313.

Bengtsson, M. and S. Kock. 2000. "'Coopetition" in Business Networks - to Cooperate and Compete Simultaneously." Industrial Marketing Management 29(5):411-426.

Borgatti, S. P. 2005. "Centrality and Network Flow." Social Networks 27(1):55-71.

Boudreau, Kevin J. 2012. "Let a Thousand Flowers Bloom? an Early Look at Large Numbers of Software App Developers and Patterns of Innovation." Organization Science 23(5):1409-1427. 
Buganza, Tommaso, Claudio Dell'Era, Elena Pellizzoni, Daniel Trabucchi, and Roberto Verganti. 2015. "Unveiling the Potentialities Provided by New Technologies: A Process to Pursue Technology Epiphanies in the Smartphone App Industry." Creativity and Innovation Management 24 (3): 391-414.

Carbonell, Javier, Antonio Sánchez-Esguevillas, and Belén Carro. 2017. "Easing the Assessment of Emerging Technologies in Technology Observatories. Findings about Patterns of Dissemination of Emerging Technologies on the Internet." Technology Analysis \& Strategic Management.1-21.

Carrión, Gabriel Cepeda, Christian Nitzl, and José L. Roldán. "Mediation Analyses in Partial Least Squares Structural Equation Modeling: Guidelines and Empirical Examples." In Partial Least Squares Path Modeling, 173-195:Springer, 2017.

Cennamo, Carmelo. 2014. "Revisiting Network Effects Theory: Towards a Strategy Perspective."Academy of Management.

Cepeda-Carrion, Ignacio, Antonio G. Leal-Millán, Silvia Martelo-Landroguez, and Antonio L. Leal-Rodriguez. 2016. "Absorptive Capacity and Value in the Banking Industry: A Multiple Mediation Model." Journal of Business Research 69(5):16441650 .

Chen, Qianling, Min Zhang, and Xiande Zhao. 2017. "Analysing Customer Behaviour in Mobile App Usage." Industrial Management \& Data Systems 117(2):425-438.

Chesbrough, Henry William. 2006. Open Innovation: The New Imperative for Creating and Profiting from Technology Harvard Business Press.

Chin, Wynne W. 1998. "The Partial Least Squares Approach to Structural Equation Modeling." Modern Methods for Business Research 295(2):295-336.

Corral, L. and I. Fronza. 2015. "Better Code for Better Apps: A Study on Source Code Quality and Market Success of Android Applications.".

Crowston, Kevin, Hala Annabi, and James Howison. 2003. "Defining Open Source Software Project Success." ICIS 2003 Proceedings:28.

Cusumano, Michael. 2010. "Technology Strategy and Management the Evolution of Platform Thinking." Communications of the ACM 53(1):32-34.

DeLone, W. H. and E. R. McLean. 1992. "Information Systems Success: The Quest for the Dependent Variable." Information Systems Research 3(1):60-95.

den Hartigh, Erik, J. Roland Ortt, Geerten van de Kaa, and Claire CM Stolwijk. 2016. "Platform Control during Battles for Market Dominance: The Case of Apple Versus IBM in the Early Personal Computer Industry." Technovation 48:4-12.

Doreian, P. 2001. "Causality in Social Network Analysis." Sociological Methods and Research 30(1):81-114. 
Dushnitsky, Gary and Thomas Klueter.2011. "Is there an eBay for Ideas? Insights from Online Knowledge Marketplaces." European Management Review 8(1):17-32.

Eisenmann, T., G. Parker, and M. Van Alstyne. 2011. "Platform Envelopment." Strategic Management Journal 32(12):1270-1285.

Evans, David S. and Richard Schmalensee. 2016. "Why Winner-Takes-All Thinking Doesn't Apply to the Platform Economy." Harvard Business Review.

Faust, K. 1997. "Centrality in Affiliation Networks."Social Networks 19(2): 157-191.

Felipe, C. M., Roldán, J. L., \& Leal-Rodríguez, A. L. 2016. “An explanatory and predictive model for organizational agility". Journal of Business Research, 69(10), 4624-4631.

Fornell, Claes and Fred L. Bookstein. 1982. "Two Structural Equation Models: LISREL and PLS Applied to Consumer Exit-Voice Theory." Journal of Marketing Research.440-452.

Freeman, L. C. 1978. "Centrality in Social Networks Conceptual Clarification." Social Networks 1(3):215-239.

Garavelli, Achille Claudio, A. Messeni Petruzzelli, Angelo Natalicchio, and Wim Vanhaverbeke. 2013. "Benefiting from Markets for ideas - an Investigation Across Different Typologies." International Journal of Innovation Management 17(6): 1340017.

Gawer, A. and M. A. Cusumano. 2014. "Industry Platforms and Ecosystem Innovation." Journal of Product Innovation Management 31(3):417-433.

Gawer, Annabelle and Michael A. Cusumano. 2002. Platform Leadership: How Intel, Microsoft, and Cisco Drive Industry Innovation Harvard Business School Press Boston.

Hair, J. F., C. M. Ringle, and M. Sarstedt. 2011. "PLS-SEM: Indeed a Silver Bullet." Journal of Marketing Theory and Practice 19(2):139-151.

Henseler, Jörg, Christian M. Ringle, and Marko Sarstedt. 2015. "A New Criterion for Assessing Discriminant Validity in Variance-Based Structural Equation Modeling." Journal of the Academy of Marketing Science 43(1):115-135.

Hu, Yuanjia, Thomas Scherngell, Lan Qiu, and Yitao Wang. 2015. "R\&D Internationalisation Patterns in the Global Pharmaceutical Industry: Evidence from a Network Analytic Perspective." Technology Analysis \& Strategic Management 27(5):532-549.

Hunt, Shelby D. 1997. "Competing through Relationships: Grounding Relationship Marketing in resource-advantage Theory." Journal of Marketing Management 13(5):431-445. 
Iansiti, M. and R. Levien. 2004. "Strategy as Ecology." Harvard Business Review 82(3).

Kim, H. and D. M. Hanssens. 2017. "Advertising and Word-of-Mouth Effects on PreLaunch Consumer Interest and Initial Sales of Experience Products." Journal of Interactive Marketing 37:57-74.

Lee, G. and T. S. Raghu. 2014. "Determinants of Mobile Apps' Success: Evidence from the App Store Market." Journal of Management Information Systems 31(2):133-169.

Lee, Sang M., Taewan Kim, Yonghwi Noh, and Byungku Lee. 2010. "Success Factors of Platform Leadership in Web 2.0 Service Business." Service Business 4(2):89-103.

Libert, B., M. Beck, and J. Wind. 2016. the Network Imperative: How to Survive and Grow in the Age of Digital Business Models Harvard Business Press Review.

McAfee, Andrew and Erik Brynjolfsson. 2012. "Big Data: The Management Revolution." Harvard Business Review 90(10):61-67.

Meyer, Marc H. and Alvin P. Lehnerd. 1997. The Power of Product Platforms Simon and Schuster.

Monroe, Kent B. 1979. Pricing: Making Profitable Decisions McGraw-Hill New York.

Nambisan, Satish and Mohanbir Sawhney. 2011. "Orchestration Processes in NetworkCentric Innovation: Evidence from the Field." The Academy of Management Perspectives 25(3):40-57.

Natalicchio, A., A. Messeni Petruzzelli, and AC Garavelli. 2014. "A Literature Review on Markets for Ideas: Emerging Characteristics and Unanswered Questions." Technovation 34(2):65-76.

Peng, David Xiaosong and Fujun Lai. 2012. "Using Partial Least Squares in Operations Management Research: A Practical Guideline and Summary of Past Research." Journal of Operations Management 30(6):467-480.

Perrons, Robert K. 2009. "The Open Kimono: How Intel Balances Trust and Power to Maintain Platform Leadership." Research Policy 38(8):1300-1312.

Petrescu, Maria. 2013. "Marketing Research using Single-Item Indicators in Structural Equation Models." Journal of Marketing Analytics 1(2):99-117.

Petsas, Thanasis, Antonis Papadogiannakis, Michalis Polychronakis, Evangelos P. Markatos, and Thomas Karagiannis. 2013. "Rise of the Planet of the Apps: A Systematic Study of the Mobile App Ecosystem."ACM.

Reinartz, W., M. Haenlein, and J. Henseler. 2009. "An Empirical Comparison of the Efficacy of Covariance-Based and Variance-Based SEM." International Journal of Research in Marketing 26(4):332-344. 
Richins, Marsha L. and Teri Root-Shaffer. 1988. "The Role of Evolvement and Opinion Leadership in Consumer Word-of-Mouth: An Implicit Model made Explicit." NAAdvances in Consumer Research Volume 15.

Ringle, C. M., M. Sarstedt, and D. W. Straub. 2012. "A Critical Look at the use of PLSSEM in MIS Quarterly." MIS Quarterly: Management Information Systems 36(1).

Ringle, Christian M., Sven Wende, and Jan-Michael Becker. 2015.SmartPLS 3.Boenningstedt: SmartPLS GmbH.

Salman, N. and A. -L Saives. 2005. "Indirect Networks: An Intangible Resource for Biotechnology Innovation." R\&D Management 35(2):203-215.

Schilling, Melissa A. 2002. "Technology Success and Failure in Winner-Take-all Markets: The Impact of Learning Orientation, Timing, and Network Externalities." Academy of Management Journal 45(2):387-398.

Shankar, V. and B. L. Bayus. 2003. "Network Effects and Competition: An Empirical Analysis of the Home Video Game Industry."Strategic Management Journal 24(4): 375-384.

Sobel, Michael E. 1982. "Asymptotic Confidence Intervals for Indirect Effects in Structural Equation Models."Sociological Methodology 13: 290-312.

Suarez, F. F. 2005. "Network Effects Revisited: The Role of Strong Ties in Technology Selection." Academy of Management Journal 48(4):710-720.

Subramaniam, C., R. Sen, and M. L. Nelson. 2009. "Determinants of Open Source Software Project Success: A Longitudinal Study." Decision Support Systems 46(2):576-585.

Trabucchi, Daniel, Tommaso Buganza, and Elena Pellizzoni. 2017. " Give Away Your Digital Services: Leveraging Big Data to Capture Value "Research Technology Management 60(2):43-52.

Trabucchi, Daniel, Tommaso Buganza, Claudio Dell'Era, and Elena Pellizzoni. 2018. " Exploring the Inbound and Outbound Strategies Enabled by User Generated Big Data: Evidence from Leading Smartphone Applications " Creativity and Innovation Management 27(1):42-55

Van Alstyne, Marshall W., Geoffrey G. Parker, and Sangeet Paul Choudary. 2016. "Pipelines, Platforms, and the New Rules of Strategy." Harvard Business Review 94(4):54-62.

Varshney, Upkar. 2014. "Mobile Health: Four Emerging Themes of Research." Decision Support Systems 66:20-35.

Vinzi, V. E., W. W. Chin, J. Henseler, and H. Wang. 2010. . Handbooks of Partial Least Squares: Concepts, Methods and Applications. Heidelberg: Springer-Verlag Berlin Heidelberg. 
Wasko, Molly McLure and Samer Faraj. 2005. "Why should I Share? Examining Social Capital and Knowledge Contribution in Electronic Networks of Practice." MIS Quarterly:35-57.

Watts, Alison. 2003. "A Dynamic Model of Network Formation." In Networks and Groups,337-345: Springer.

Wellman, Barry and Stephen D. Berkowitz. 1988. Social Structures: A Network Approach. Vol. 2 CUP Archive.

Whelan, E., R. Teigland, B. Donnellan, and W. Golden. 2010. "How Internet Technologies Impact Information Flows in R\&D: Reconsidering the Technological Gatekeeper." R\&D Management 40(4):400-413.

\section{ACKNOWLEDGEMENTS}

The authors would like to acknowledge Valeria Gallina, who provided a valuable contribution in early stages of this research.

\section{AUTHORS BIOGRAPHIES}

\section{Elena Pellizzoni}

Elena Pellizzoni is Assistant Professor at the School of Management of Politecnico di Milano where she serves as a researcher of LEADIN'Lab, the Laboratory for Leadership, Design and Innovation. Her research interests are focused in innovation Management. In particular, she has been working on self-engagement innovation activity such as innovation contests, calls for ideas, and idea management systems. She is also focused on 
mechanisms of value creation and appropriation in mobile apps and the role of the interplay between technology and meaning in high-tech industries.

\section{Daniel Trabucchi}

Daniel Trabucchi is a PhD Student at the School of Management of Politecnico di Milano, where he serves as a researcher of LEADIN'Lab, the Laboratory for Leadership, Design and Innovation. His research interests are focused in Innovation Management. In particular, he has been working on the impact of digital technologies and big data on Two-sided market business model, moreover he focuses on innovation strategy based on the interplay between technology and meaning. His research has been published in peerreviewed journals such as Research-Technology Management, Creativity and Innovation Management and European Journal of Innovation Management; he is also a reviewer for many of these journals.

\section{Tommaso Buganza}

Tommaso Buganza is Associate Professor of Leadership and Innovation at the School of Management of Politecnico di Milano where he also is co-founder of LEADIN'Lab, the Laboratory for Leadership, Design and Innovation. He is a lecturer in Innovation Management and Project Management, responsible for the Project Management Academy and coordinator of the innovation and training area at MIP (Politecnico di Milano Graduate School of Business). He is a member of the scientific committee of the International Product Development Management Conference EIASM-IPDMC. His research activity explores the intersection between technological innovation and leadership and has been published in peer-reviewed journals such as Journal of Product Innovation Management, International Journal of Project Management, International Journal of Innovation Management, European Journal of Innovation Management, and Creativity and Innovation Management, and in a number of books; he is also a reviewer for many of these journals. 